\title{
COVID-19 pandemic: Current and future implications on science and society
}

\author{
Nafeesa Safdar ${ }^{1}$, Aiman Zahra ${ }^{2}$ and Tanveer Hussain ${ }^{1 *}$ \\ 1. Department of Molecular Biology, Virtual University of Pakistan, Lahore, Pakistan \\ 2. Department of Biology, Virtual University of Pakistan, Lahore, Pakistan \\ *Corresponding author's email: tanveer.hussain@vu.edu.pk \\ Citation \\ Nafeesa Safdar, Aiman Zahra and Tanveer Hussain. COVID-19 pandemic: Current and future implications on \\ science and society. Pure and Applied Biology. Vol. 10, Issue 2, pp388-398. \\ http://dx.doi.org/10.19045/bspab.2021.100042
}

Received: 09/06/2020 Revised: 11/08/2020

Accepted: $25 / 09 / 2020$

Online First: 30/09/2020

\section{Abstract}

In $1^{\text {st }}$ quarter of $21^{\text {st }}$ century, with the appearance of novel coronavirus, the world is facing a disastrous pandemic of COVID-19 originated from China. The pandemic intensity differs from country to country and the most affected countries are Italy, Spain, France, UK and USA in terms of the mortality ratio while virus is spreading rapidly in more than 180 countries of Europe, Australia, North and South American, Asia and least affecting the African continents. In Pakistan, there have been total 2,389,827 active infections, 1,446,574 recoveries and 280,697 deaths worldwide to date (10/05/2020) which is more than severe acute respiratory syndrome (SARS) and Middle East respiratory syndrome (MERS). The outbreak of SARS, affected 8098 individuals with 774 deaths and 9.7\% fatality rate while MERS-CoV has 2494 cases, 858 deaths and $34 \%$ fatality rate. The COVID-19 epidemic has established anxious condition all over the world which exhibited the adverse effects on physical and mental health of individuals. This review discusses comparative analysis of confirmed cases, number of deaths and highlighting the impact of COVID-19 on daily life, international trade, business, education, transport and global economy. This article summarizes the present state of information and will enhance our knowledge to understand the COVID-19 distinctive features and improve our preventive measures in future. Thus, during this period of great stress, there is requirement of new interdisciplinary methodology with collaboration of sociologists, scholars, epidemiologists, anthropologists, public health experts and virologists to have a change in our activities and behavior to environment in confronting an emergency.

Keywords: COVID-19; Deaths; Economy; Mortality; Pandemic

\section{Introduction}

Reemergence of pathogens in the form of outbreak always become worldwide challenges and troublesome issue for public health [1]. Outbreak of a disease occurs when large number of cases is reported above the expected level .Outbreaks provide an opportunity of new research to cope with situation and make discoveries about the trending [2]. In the earliest month of 2020 the international public health agency named World Health Organization announced sixth outbreak emergency of disease COVID-19 all over the world, become a public health concern. It is the sixth one outbreak from previous decades [3].

Coronaviruses has non-segmented positivesense ssRNA widely distributed among 
human beings [4]. There are six species of coronavirus comprising NL63, 229E, HKU1, and OC43, SARS-CoV, MERS$\mathrm{CoV}$. Among six, the first four are more prevailing and mainly cause normal cold like indications among healthy persons. It has been found that there was an epidemic of severe Acute Respiratory Syndrome Coronavirus (SARS-CoV) in 2002-2003 in China. Similarly, MERS-CoV was the causative agent of respiratory disease in Middle East health [1]. Now, it is the $3^{\text {rd }}$ time amongst several decades, a coronavirus of zoonotic origin has species to transmit disease to human populaces worldwide. Chinese researchers subjected that this virus with different names like Wuhan coronavirus (due to outbreak in Wuhan) or it may be 2019 novel coronavirus [5]. Chinese government named this disease as novel coronavirus pneumonia (NCP) because it affects lower respiratory tract [6]. The WHO declared that the official name of novel coronavirus is coronavirus disease (COVID19) [7]. However, the International Committee on Taxonomy of Viruses (ICTV) declared that it the SARS-CoV-2 virus as it is closely related to SARS outbreak (SARS-CoVs) [8].

The WHO announced that the outbreak of the coronavirus epidemic was linked with the Huanan South China, but there is no specific animal association has been reported. In January 2020, a huge number of cases of novel coronavirus have been reported in Wuhan, China. There were very few cases which were identified on December 29, 2019; all were belonging to Seafood Wholesale Market [9].

This study is conducted on observational base and concluded that COVID-19 pandemic, a viral disease transmitted person to person, affected the world by making imbalance in the social, economic, educational, recreational aspects of life. The aim of this study is to make aware for strategies to cope with the trending situation as if remains so there will be more anxiety regarding life existence.

\section{COVID-19 general perspective}

In the previous eighteen years, the world has seen three lethal epidemics of developing coronaviruses, notorious to originate intestinal and respiratory intricacies in people [10]. The outbreak of COVID-19 turned into a severe threat for the medicinal services specialists, academic network, scientists and the diseases controlling offices across the world, as far as spread, prevention and treatment. Pneumonia seems, by all accounts, to be the most continual indication of disease, described basically by cough, reciprocal invades chest imaging, dyspnea and fever [11]. The general case casualty rate is unsure however gives off an impression of being around 3 percent. The vast majority of the fatal cases have happened in patients with fundamental clinical comorbidities. However, the COVID-19 epidemic is damaging the mental as well as physical health, while, the healthcare specialists are mainly concentrating on physical health [12]. Reemergence of pathogens in form of outbreak always become worldwide challenges and troublesome issue for public [13].

Outbreak of a disease occurs when large number of cases is reported above level that might be expected to be present in community. Outbreaks provide an opportunity of new research to cope with situation and make discoveries about the trending disease regarding its treatment, control, vaccine development [14]. In the earliest month of 2020 the international public health agency named World Health Organization announced sixth outbreak emergency of disease COVID-19 all over the world, turn out to be a public health fear [15]. It is the sixth one outbreak from previous decades that were of $\mathrm{H} 1 \mathrm{~N} 1$, polio, 
Ebola in West Africa, Zika /Ebola in Congo and novel coronavirus of 2019.The World Health Organization announced COVID-19 as pandemic on March 11, 2020 [16]. The occurrence of coronavirus epidemic (COVID-19) on the worldwide public health scene has prompted developing concerns and vulnerabilities. The COVID-19 pandemic expanded realization that an outbreak doesn't have any citizenship and that we are completely associated as one 'worldwide country'. It is bitter truth that coronavirus has claimed a number of lives due to its devastating and rapidly mutating nature and still tainting the individuals too [17]. Since the first case showed up in the end of December 2019, COVID-19 has brought broad shock on clinical and public health frameworks that cope to counter to the flow [18].

Total seven European and one Asian country are among the 10 most coronavirus afflicted countries, while progressively European countries are seeing a rise in number of cases [19]. The US supplanted China as the country with the most elevated coronavirus cases on March 26,2020, while over $92 \%$ of the worldwide coronavirus cases at present are outside China [20]. Coronavirus keeps on being serious in Italy, making it the mostinfluenced in Europe as well outside Asia. Italy has seen the highest death rate due to COVID-19 on the planet [21].

Today, COVID-19 outbreak is a main public health risk, with 280,867 deaths and $4,120,485$ confirmed cases globally till May 10, 2020 (worldometers info, 2020). Since the primary documentation of the virus in China, worldwide transmission has been increased, with 182/202 countries getting announced minimum one case. The practice in countries to date has highlighted the extreme stress that a COVID-19 pandemic sites on national health organizations, with requirement for exhaustive care beds and mechanical ventilators quickly surpassing their accessibility in comparatively extremely resourced situations. This has possibly reflective significances for resource poor situations, where the value and accessibility of healthcare and interrelated properties for example oxygen ventilators are usually poorer [22].

\section{Impact of COVID-19 vs SARS: Learning from past}

The world encountered the epidemics of coronavirus disease that undermine worldwide pandemics of Severe Acute Respiratory Syndrome (SARS) from 2002 to 2003 and Middle East Respiratory Syndrome (MERS) in 2011 [23]. In both of these cases, the pathogen (SARS-CoV and MERS-CoV, individually) were recently diagnosed coronavirus in the family Betacoronavirus with zoonotic inception [24]. The world is strongly in the grasp of the pandemic COVID-19. Commonly, Coronaviruses are an enormous group of enveloped RNA viruses that for the most part infect mammals and birds. In people, they can cause light infestation in the upper respiratory tract, similar to the normal cold, yet in addition increasingly severe lower respiratory tract diseases. These infestations can show as pneumonia, bronchitis or an extreme respiratory ailment, for example, Middle East respiratory syndrome (MERS), severe acute respiratory syndrome (SARS), or coronavirus- 19 (COVID-19). Despite the fact that the fatality rate is far lower than that of MERS (34.4\%) and SARS (9.14\%), the combined affirmed cases, in a period of around 2 months after the pandemic, especially surpassed SARS with 8,096 cases since 2002 and MERS with 2,494 cases since 2012. The virus named SARS-CoV-2 shares sequence similarity of about 88 percent to that of 2 coronaviruses identified in bats while it shows 79 percent similarity with the SARS coronavirus and have also depicted 50 percent similarity with MERS coronavirus. The profoundly infectious 
nature of SAR-CoV-2 is presumably because of the infection spreading through asymptomatic infected person which has been accounted for in Germany. Perception of 88 cases analyzed during 20-28th January, 2020 from people with Wuhan travel history, found that the mean incubating period extended from 2.1 to 11.1 days, which is like another study and was in a similar range with SARS-CoV and MERS$\mathrm{CoV}$ [25]. Coronavirus transmission in individual seems competent and the virus is of epidemic potential. Till now, public health processes in China and other pretentious zones are still incapable to stop the transmission of human infestation [26]. There is huge anxiety that virus spread may be overwhelming and of great public health apprehensions worldwide, particularly in resource restricted countries [27].

\section{Coronavirus situation in Pakistan}

On January24, 2020 a person was diagnosed for novel coronavirus with the travelling history from China [28]. A large number of cases reported in pilgrims with travel history from Iran, another border sharing country with Pakistan [29].

At present, up to up to the $10^{\text {th }}$ of May, there are 29,465 confirmed cases, 639 deaths and 8023 recoveries. These are the number of cases reported from $24^{\text {th }}$ January 2020 (when first case reported) to $10^{\text {th }}$ May, 2020 (Worldometer, Pakistan 2020). Punjab has the maximum number of cases while Khyber Pakhtunkhwa has highest number of deaths. Among cities Lahore (Punjab) has the maximum number of cases [30]. General analysis from rapidly increasing cases was done at $15^{\text {th }}$ April; mortality rate due to corona virus in Pakistan was $1.6 \%$ while recovery rate was $15.6 \%$.which is insignificant as compared to other countries like Italy and America. Thus, till than the recovery rate was 14 times higher that mortality rate and this is a positive impact on the overall situation. However, the number of cases are increasing that will become alarming near future [31]. Number of infections can go a lot (extremely much) higher in significant major areas of Pakistan comparing with a considerable lot of different countries. Fatality rate (as percentage of affirmed cases) would likely be significantly less in Pakistan. If circumstance like Italy begins occurring in Pakistan and number of cases in Lahore, Karachi, and Rawalpindi exceeding a specific verge, we can easily access the number of coronavirus cases assessed in this segment, however, preventive measure are taken ahead of time [32]. There might be different reasons of less number of reported cases of COVID-19 in Pakistan compared to Iran \& China. First, the first case of corona in Pakistan appeared later than China, Iran and the country got reasonable time to get itself ready for coping with this pandemic condition. Second, the number of foreign visitors was quite less in Pakistan compared to its neighbors which reduced the chances of human trafficking with this zoonotic illness. Third, almost $70 \%$ population of Pakistan live in rural areas while Iran \& China have more urban population which live in high stories buildings and also use subway transport network. Rural inhabitants have less chances of close contacts of majority people while urban population remain at risk of contagious diseases due to close contacts in buildings and transport networks. Forth, Pakistan lacked the required diagnostic facilities; although, it is testing samples from suspected cases in the WHO selected COVID-19 test centers and at NIH, leading diagnostic lab but still a large number of infected cases might have no awareness or access to the testing laboratories [33].

After almost four months' time, Pakistan like other part of developing world is fighting with the growing hazard of Covid19 with limited resources effectively. We 
may also have no exact idea, for how long Pakistan can fight against the Covid-19. One thing is clear that at present the Covid-19 related death ratio is very low in Pakistan [34]. The hazard of Covid-19 is on the way toward increase and we have to stop it somewhere. Pakistan, being a poor country is not in a position to go for such a comprehensive lockdown. Therefore, Pakistan has arranged and managed a partial lockdown. Looking into the ongoing epidemiological trend, we can say that death ratio in Pakistan is comparatively moderate [35]. This may be attributed to the uniqueness in immune system, partial lockdown and self-quarantine observed in Pakistan?

People in general have been encouraged to maintain a strategic distance from every mass social occasion, including religious get together. All schools and colleges have been closed for a time, and both administrative and common governments have actualized measures to contain and relieve the spread of the infection [36].

Comparative analysis of COVID-19 situation across different countries

As coronavirus begins to increase a more tightly hold on the world outside of China, numbers of revealed infections and deaths are on the ascent [37]. Affirmed novel coronavirus reports extended 10 times within a month, as of 100,000 in the first7 day stretch of March to greater than a million till April 02, 2020, though greater than 52,000 demises have been reported across the globe. European countries have turn into the new central point of COVID19. While examining, more than 208,000 persons have expired due to coronavirus, the infection caused by the new COVID-19, though some 3,000,000 diseases have been declared in 185 countries and regions with addition of 878,000 patients have improved to date (Coronavirus: confirmed global cases pass one million, 2020).
On $31^{\text {st }}$ January, 2020, in the United Kingdom (UK) the primary 2 cases of coronavirus were affirmed in the Humber and Yorkshire area, at that time the cases in this area have augmented to 8,891 . London has the maximum reported virus cases in the UK with 23,608 documented cases, although the South East and North West have 15,810 and 17,089 reported cases correspondingly. The coronavirus has until now been accountable for 20,732 United Kingdom as of $26^{\text {th }}$ April, 2020, with 122,012 demises happening through the entire Europe (Coronavirus death rate worldwide, Statista, 2020) [38].

COVID-19 mortality ratio exhibited the diverse severity in the world. In Europe, Italy has the maximum number of cases, and proclaimed a sequence of extreme procedures above the weekend to attempt to cover the epidemic. There were 108,237 people getting better at home or being cured in hospital. According to US-based Johns Hopkins University, while following the epidemic globally, reported that more than 28,000 individuals have been died so far due to coronavirus in Italy [39].

The first case of SARS-2 pandemic reported in North America in month of January 2020 in United States and claimed a number of lives and still on the way to threat to million more both in U.S and Canada.Almost all countries of North America were affected by this pandemic including Saint Kitts, Nevis and Bonaire .With time, particularly , on 26 March 2020 the United States became to have highest number of cases that were over 82,000 . This situation became more tragic and officially United States became the most affected country of North America with death toll of over 20,000 individuals (COVID-19 pandemic in North America, 2020).

In the Middle East, Iran's outbreak has been the most awful so far and there are anxieties that the epidemic's extent is considerably 
poorer than stated by Iranian establishments. Iran had stated 84,802 cases through altogether thirty one provinces, with 5,297 demises on April 21, 2020.Even with its rigorousness, maximum individuals experience minor symptoms and improve, but the aged and those with prior existing disorders are predominantly susceptible to the virus [40]. The novel coronavirus, COVID-19, by this time has spread to more than 180 countries and regions across the world at this stage of writing. However, some countries like South Korea and China look to have controlled the virus such as the number of novel cases are reducing promptly, in other regions of the ecosphere, it is just in progress of developing exponentially [41].

\section{COVID-19: Disrupting lives, economies} and societies

The worldwide epidemic is swaying an extensive area of universal economy and exchange enterprises, from services usually to the hospitality and travel, clinical materials and international value chains, financial markets, consumer electronics, energy, food, social activities, transportation to give some examples [42]. The Organization for Economic Co-operation and development (OECD) Secretary General Angel Gurria expressed On March 23, 2020 that "The sheer size of the current threat acquaints a phenomenal multifaceted nature to financial forecasting. The Organization for Economic Co-operation and development (OECD )Interim Economic Outlook, discharged on March 2, 2020, made a first endeavor to check out the imaginable effect of COVID-19 on worldwide development, yet it currently appears like we have just moved well past even the more serious situation visualized at that point. The pandemic has additionally gotten under way a significant financial emergency that will trouble our social orders for a considerable length of time to come" [43].

The International Monetary Fund Organization (IMF) stated that the global economy would come across its "most exceedingly recession since the extreme anxiety, outstripping that observed throughout the worldwide economical emergency ten years back." Moreover, the IMF conjecture assessed that the global economy might decline by $3.0 \%$ in 2020 , prior evolving by 5.8 percent in 2021; universal exchange is expected to decrease in 2020 by $11.0 \%$ and oil prices are predicted to decrease by 42 percent. The unexpected financial interruption brought about by COVID-19 isn't just ruinous yet additionally has spillover suggestions since it made supply and requirements shock in pretty much every region of human endeavor [44]. The financial fallout around the globe because of the infection could include downturns for the Japan, US and euro-region, the slowest progress reported in China, and a cumulative of $\$ 2.7$ trillion in lost profit - equivalent to the total GDP of the UK. China will continue to survive as a result of its enormous reserves (Tackeling coronavirus, 2020). Pakistan is a developing country which has been undergoing several crises for the previous many years. However, economy of Pakistan is nowadays on ventilator, COVID-19 which is causing the world economy to a downfall, can destroy our economy like it demolished immune system of human body and also this monster will smash harshly and make irretrievable threat and all at the same interval. Pakistan as specified by rough estimates might cause primary economic loss of 1.3tr rupees because of COVID-19 [45].

Keeping in notice the ascent in Italy's death rate, the wellbeing indicators around the globe are underscoring on complete lockdown around the state while we can't 
bear to practice such lockouts given that we can confront enormous financial shortfall as our assets are constrained and economy is crumbling [46].

One of the most significant results of the Coronavirus epidemic is the development of social tension around the world. This has prompted severe threat for people of all countries, even in communities without an affirmed outbreak [47]. The feeling of dissatisfaction particularly among the young age group proclaims how our communities are defenseless in confronting hazards. Old and aged individuals, impaired and lowsalary people endure unbalanced harm in disasters and outbreaks on account of Corona pandemics, all gatherings in societies think that they are in danger [48]. There is requirement of new interdisciplinary methodology with collaboration of sociologists, scholars, epidemiologists, anthropologists, public health experts and virologists to have a change in our activities and behavior to environment in confronting an emergency [49].

COVID-19 pandemic has upset the lives of numerous individuals over the world. The overall quick increase of infected cases has made a feeling of vulnerability and nervousness about what will happen [50]. COVID-19 has additionally influenced all degrees of the educational framework from primary school to tertiary education [51]. Various countries have had various strategies going from complete lock-down in Italy and Germany to targeted shut down in the United Kingdom for everything except staff in key industries with more than hundred countries forcing closure of educational institutes across the nation [52]. UNESCO assesses that near 900 million students have been influenced by the educational department closure. While discussing Effect on undergrad education, the most critical effect is on the postgraduate research network with research into numerous non-COVID related subjects delayed or suspended. This pressure may prompt troublesome impacts on the learning and mental health of students [53].

International students staying away from home are not just stressed about their safety, education and health yet they additionally have an immense number of worries for the health of their families [54]. The COVID-19 pandemic may seriously affect the careers of this present years' college and university graduates. They are encountering significant interruptions in educating and evaluation in the last part of their examinations. They may probably graduate late because of the delay of the last examination. Moreover, the alumni are going to confront the serious difficulties of the worldwide downturn brought about by the COVID-19 emergency [55].

Status and challenges toward vaccine development in wake of COVID-19

Now, the world looks for a perspective to stop the COVID-19 outbreak, the struggle is on to find out and generate a vaccine. A few idealistic assumptions recommend that vaccine could be available in a year or even in six months - however researchers are now warning that it perhaps won't be honestly believable to develop enough vaccine for everyone, rich countries may gather supplies [56]. Assets for coronavirus, will likewise must be adjusted against the requirement for different vaccines. In the event that vaccines created from inactivated types of SARS-CoV-2 demonstrate best, it ought to be simpler to assess what it would take to produce dosages, since this mechanical innovation has been around since at least the $1950 \mathrm{~s}$, the creation and purification of entire SARS-CoV-2 infection at high concentrations could require resources with biosafety level 3 accreditation [57]. 
These are rare, and could be the reason not much organizations state they are attempting this methodology. But even if huge amount of vaccine is made, there is no real way to constrain countries to share it. During the 2009 H1N1 flu outbreak, Australia was among the first to create a vaccine, yet didn't promptly export it since it needed vaccines for its residents first. There is likewise no worldwide entity responsible for requesting the assembling of vaccines on a worldwide scale and paying for it $[58,59]$.

\section{Conclusion}

The current pandemic of COVID-19 has been considered as global health threat. The number of confirmed cases is continuously increasing all over the world. It is possibly evident that lockdown only might not be satisfactory to stop the spread of COVID-19, as the global effect of this virus transmission is one of intensifying apprehension. Advance study is certainly necessary to help in describing the particular animal to human and human to human transmission mechanisms to facilitate the vaccine development. As the painful situation of this pandemic alarmed the world and there is dire need of attention towards various aspects regarding the control of this pandemic not only at national level but also at international. Additionally, virus outbreaks in future are possible to continue, efforts are needed to develop comprehensive strategies to prevent these pandemics in future.

\section{Authors' contributions}

Conceived and designed the experiments: $\mathrm{T}$ Hussain \& N Safdar, Performed the experiments: N Safdar, Analyzed the data: A Zahra \& T Hussain, Wrote the paper: N Safdar, A Zahra \& T Hussain.

\section{References}

1. Zhu N, Zhang D, Wang W, Li X, Yang B, Song J \& Niu P (2020). A novel coronavirus from patients with pneumonia in China, (2019). New Engl J Med 382(8): 727-33.

2. Smith KF, Goldberg M, Rosenthal S, Carlson L, Chen J, Chen C \& Ramachandran S (2014). Global rise in human infectious disease outbreaks. $J R$ Soc Interface 11(101): 1-7.

3. Rabi FA, Al Zoubi MS, Kasasbeh GA, Salameh DM \& Al-Nasser AD (2020). SARS-CoV-2 and coronavirus disease 2019: What we know so far. Pathogens 9(3): 231-237.

4. Huang C, Wang Y, Li X, Ren L, Zhao J, $\mathrm{Hu}$ Y \& Cheng Z (2020). Clinical features of patients infected with 2019 novel coronavirus in Wuhan, China. Lancet 395(10223): 497-506.

5. Shereen MA, Khan S, Kazmi A, Bashir N \& Siddique R (2020). COVID-19 infection: origin, transmission, and characteristics of human coronaviruses. J Adv Res 24(1): 91-98.

6. Yuen KS, Ye ZW, Fung SY, Chan CP \& Jin DY (2020). SARS-CoV-2 and COVID-19: The most important research questions. Cell Biosci 10(1): 15.

7. Li F (2016). Structure, function, and evolution of coronavirus spike proteins. Annu Rev Virol 3: 237-261.

8. Abbas G, Iqbal A, Javid MA, Saleem W \& Shahzad MK. Covid-19 Attack, Prevention, Precaution and Managemental Strategies. Int J Innov Educ Res 7(3): 148-162.

9. Li Q, Guan X, Wu P, Wang X, Zhou L, Tong Y \& Xing X (2020). Early transmission dynamics in Wuhan, China, of novel coronavirus-infected pneumonia. $N$ Engl J Med 382: 11991207.

10. Raoult D, Zumla A, Locatelli F, Ippolito G \& Kroemer G (2020). Coronavirus infections:

Epidemiological, clinical and 
immunological features and hypotheses. Cell Stress 4(4): 66-69.

11. Wu Z \& McGoogan JM (2020). Characteristics of and important lessons from the coronavirus disease 2019 (COVID-19) outbreak in China: summary of a report of 72314 cases from the Chinese Center for Disease Control and Prevention. JAMA 323(13): 1239-1242.

12. Guan WJ, Liang WH, Zhao Y, Liang HR, Chen ZS, Li YM \& Ou CQ (2020). Comorbidity and its impact on 1590 patients with Covid-19 in China: A Nationwide Analysis. Eur Respir J 55(5): 1-14.

13. Bloom DE \& Cadarette D (2019). Infectious Disease Threats in the 21st Century: Strengthening the Global Response. Front Immunol 10(2019): 549-557.

14. Brachman PS (2003). Infectious diseases - past, present, and future. Int J Epidemiol 32(5): 684-686.

15. Sohrabi C, Alsafi Z, O’Neill N, Khan M, Kerwan A, Al-Jabir A \& Agha R (2020). World Health Organization declares global emergency: A review of the 2019 novel coronavirus (COVID19). Int J Surg 76: 71-72.

16. Jebril N (2020). World Health Organization declared a pandemic public health menace: A systematic review of the coronavirus disease 2019 "COVID-19", up to 26th March 2020. Psychosoc Rehabil J 24(9): 1475-7192.

17. Atere AD, Oduwole OA, Okpoli HC \& Hassan AO (2020). CORONAVIRUS: Resilient Nightmare of the COVID-19 Pandemic in Africa. Sokoto J Med Lab Sci 30(1): 90-95.

18. Khurshid A (2020). Applying Blockchain Technology to Address the Crisis of Trust During the COVID-19 Pandemic. J Med Internet Res 8(9): 1-9.
19. Munster VJ, Koopmans M, Van Doremalen N, Van Riel D \& De Wit E (2020). A novel coronavirus emerging in China-key questions for impact assessment. N Engl J Med 382(8): 692694.

20. Angelopoulos AN, Pathak R, Varma R, \& Jordan MI (2020). Identifying and Correcting Bias from Time-and Severity-Dependent Reporting Rates in the Estimation of the COVID-19 Case Fatality Rate. ArXiv 6(1): 1-23.

21. Remuzzi A \& Remuzzi G (2020). COVID-19 and Italy: what next? Lancet Haematol 395(10231): 1225-1228.

22. Dahab M, van Zandvoort K, Flasche S, Warsame A, Ratnayake R, Favas C \& Checchi F (2020). COVID-19 control in low-income settings and displaced populations: what can realistically be done? Confl Health 14(1): 1-6.

23. Schwartz DA \& Graham AL (2020). Potential maternal and infant outcomes from (Wuhan) coronavirus 2019-nCoV infecting pregnant women: lessons from SARS, MERS, and other human coronavirus infections. Viruses 12(2): 194-202.

24. Zumla A, Hui DS \& Perlman S (2015). Middle East respiratory syndrome. Lancet Infect Dis 386(9997): 995-1007.

25. Wen W, Su W, Tang H, Le W, Zhang X, Zheng Y \& Dong L (2020). Immune cell profiling of COVID-19 patients in the recovery stage by single-cell sequencing. Cell Discov 6(1): 1-18.

26. Hua J \& Shaw R (2020). Corona virus (Covid-19)"infodemic" and emerging issues through a data lens: The case of china. Int $J$ Environ Res Pub Health 17(7): 1-12.

27. Saha T, Bhuiya RH, Masum ZU, Islam MR \& Chowdhury JA(2017). Hospital pharmacy management system and future development approaches in 
bangladeshi hospital. Dhaka Univ J Pharm Sci 20(2): 180-187.

28. Rodriguez-Morales AJ, Cardona-Ospina JA, Gutiérrez-Ocampo E, VillamizarPeña R, Holguin-Rivera Y, EscaleraAntezana JP \& Paniz-Mondolfi A (2020). Clinical, laboratory and imaging features of COVID-19: A systematic review and meta-analysis. Travel Med Infect Dis 34: 1-14.

29. Arab-Mazar Z, Sah R, Rabaan AA, Dhama K \& Rodriguez-Morales AJ (2020). Mapping the incidence of the COVID-19 hotspot in Iran-Implications for Travellers. Travel Med Infect Dis 34: 1-7.

30. Baig AM, Khaleeq A, Ali U \& Syeda H (2020). Evidence of the COVID-19 virus targeting the CNS: tissue distribution, host-virus interaction, and proposed neurotropic mechanisms. ACS Chem Neurosci 11(7): 995-998.

31. Mostafa N. (2018). Critical Care Medicine: Bangladesh Perspective. $A d v$ $J$ Emerg Med 2(3): 1-2

32. Deshwal VK (2020). COVID 19: A comparative study of Asian, European, American continent. Int J Sci Res Eng Dev 3(2): 436-440.

33. Musinguzi G \& Asamoah BO (2020). The Science of Social Distancing and Total Lock Down: Does it Work? Whom does it Benefit? Electron J Gen Med 17(6): 7895-7897.

34. Nafees M \& Khan F (2020). Pakistan's Response to COVID-19 Pandemic and Efficacy of Quarantine and Partial Lockdown: A Review. Electron J Gen Med 17(6): 1-12.

35. Mukhtar S \& Mukhtar S (2020). Letter to the Editor: Mental Health and Psychological Distress in People with Diabetes during COVID19. Metabolism 108: 248-254.

36. Rokade M \& Khandagale P (2020). Coronavirus Disease: A Review of a
New Threat to Public Health. Asian J Pharm Clin Res 10(3): 241-244.

37. Lescure FX, Bouadma L, Nguyen D, Parisey M, Wicky PH, Behillil S \& Enouf V (2020). Clinical and virological data of the first cases of COVID-19 in Europe: a case series. Lancet Infect Dis 20(6): 697706.

38. Kinross P, Suetens C, Dias JG, Alexakis L, Wijermans A, Colzani E \& Monnet DL (2020). Rapidly increasing cumulative incidence of coronavirus disease (COVID-19) in the European Union/European Economic Area and the United Kingdom, 1 January to 15 March 2020. Euro Surveill 25(11): 285291.

39. Onder G, Rezza G \& Brusaferro S (2020). Case-fatality rate and characteristics of patients dying in relation to COVID-19 in Italy. JAMA 323(18): 1775-6.

40. Takian A, Raoofi A \& KazempourArdebili S (2020). COVID-19 battle during the toughest sanctions against Iran. Lancet 395(10229): 1035-1038.

41. Raoofi A, Takian A, Sari AA, Olyaeemanesh A, Haghighi H \& Aarabi M (2020). COVID-19 pandemic and comparative health policy learning in Iran. Arch Iran Med 23(4): 220-234.

42. Guo YR, Cao QD, Hong ZS, Tan YY, Chen SD, Jin HJ \& Yan Y (2020). The origin, transmission and clinical therapies on coronavirus disease 2019 (COVID-19) outbreak-an update on the status. Mil Med Res 7(1): 1-10.

43. Nicola M, Alsafi Z, Sohrabi C, Kerwan A, Al-Jabir A, Iosifidis C \& Agha R (2020). The socio-economic implications of the coronavirus pandemic (COVID-19): A review. Int J Surg 78(1): 185-193.

44. Anderson RM, Heesterbeek H, Klinkenberg D \& Hollingsworth TD 
(2020). How will country-based mitigation measures influence the course of the COVID-19 epidemic? Lancet Microbe 395(10228): 931-934.

45. Gostin LO \& Wiley LF (2020). Governmental public health powers during the COVID-19 pandemic: stayat-home orders, business closures, and travel restrictions. JAMA 323(21): 2137-2138.

46. Ahmed SA, Ajisola M, Azeem K, Bakibinga P, Chen YF, Choudhury NN \& Lilford RJ (2020). Impact of the societal response to COVID-19 on access to healthcare for non-COVID-19 health issues in slum communities of Bangladesh, Kenya, Nigeria and Pakistan: results of pre-COVID and COVID-19 lockdown stakeholder engagements. BMJ Glob Health 5(8): 42-51.

47. La YK, Choi YH, Chu MK, Nam JM, Choi YC, \& Kim WJ (2020). Gender differences influence over insomnia in Korean population: A cross-sectional study. PLoS One 15(1): 190-197.

48. Duan L \& Zhu G (2020). Psychological interventions for people affected by the COVID-19 epidemic. Lancet Psychiatry 7(4): 300-302.

49. Liu S, Yang L, Zhang C, Xiang YT, Liu Z, Hu S \& Zhang B (2020). Online mental health services in China during the COVID-19 outbreak. Lancet Psychiatry 7(4): e17-e18.

50. Zandifar A \& Badrfam R (2020). Iranian mental health during the COVID-19 epidemic. Asian J Psychiatr 51: 101-111.

51. Sintema EJ (2020). Effect of COVID19 on the Performance of Grade 12 Students: Implications for STEM Education. Eurasia J Math Sci Technol Educ 16(7): 1-6.
52. Boccia S, Ricciardi W \& Ioannidis JP (2020). What other countries can learn from Italy during the COVID-19 pandemic. JAMA Intern Med 180(7): 927-928.

53. Cao W, Fang Z, Hou G, Han M, Xu X, Dong J \& Zheng J (2020). The psychological impact of the COVID-19 epidemic on college students in China. Psychiatry Res 287: 1-5.

54. Chinazzi M, Davis JT, Ajelli M, Gioannini C, Litvinova M, Merler S \& Viboud C (2020). The effect of travel restrictions on the spread of the 2019 novel coronavirus (COVID-19) outbreak. Sci 368(6489): 395-400.

55. Perkins A, Kelly S, Dumbleton H \& Whitfield S (2020). Pandemic pupils: COVID-19 and the impact on student paramedics. Australas J Paramedicine 17(1): 1-4.

56. Cohen J (2020). Vaccine designers take first shots at COVID-19. Sci 368(6486): 14-16.

57. Prompetchara E, Ketloy C \& Palaga $T$ (2020). Immune responses in COVID19 and potential vaccines: Lessons learned from SARS and MERS epidemic. Asian Pac $J$ Allergy Immunol 38(1): 1-9.

58. Mourya DT, Sapkal G, Yadav PD,Belani SKM, Shete A \& Gupta N (2020). Biorisk assessment for infrastructure \& biosafety requirements for the laboratories providing coronavirus SARS-CoV-2/(COVID-19) diagnosis. Indian J Med Res 151(2): 172-179.

59. Holland K \& Blood RW (2013). Public responses and reflexivity during the Swine flu pandemic in Australia. $J$ Stud 14(4): 523-538. 